\title{
Reduced expression of liver kinase B1 and Beclin1 is associated with the poor survival of patients with non-small cell lung cancer
}

\author{
LILI JIANG, XUAN LIANG, MENGJIE LIU, WENJUAN WANG, JIEQUN MA, \\ QIANQIAN GUO, LILI HAN, CHENGCHENG YANG and KEJUN NAN \\ Department of Oncology, The First Affiliated Hospital of the Medical College of \\ Xi'an Jiaotong University, Xi'an, Shaanxi 710061, P.R. China
}

Received May 7, 2014; Accepted July 28, 2014

DOI: $10.3892 /$ or.2014.3432

\begin{abstract}
Liver kinase B1 (LKB1) regulates cell polarity and has tumor-suppressor functions, while Beclin1 regulates autophagy and is associated with tumorigenesis. The present study quantified the expression level of LKB1 and Beclin1 in non-small cell lung cancer (NSCLC) tissue specimens and examined the possible association with clinicopathological characteristics and the survival of patients. Quantitative real-time reverse transcriptase-polymerase chain reaction (qRT-PCR), western blotting and immunohistochemistry were used to assess expression of LKB1 and Beclin1 in 142 NSCLC tissue samples. The data revealed that expression levels of both LKB1 and Beclin1 mRNA and protein were significantly reduced in the NSCLC tissues compared to levels in the matched surrounding normal lung tissues, and expression of LKB1 protein was associated with Beclin1 expression in the NSCLC tissues. Reduced expression of LKB1 protein was significantly associated with tumor histology $(\mathrm{P}<0.001)$ and poor differentiation $(\mathrm{P}<0.001)$, but was not associated with tumor lymph node metastasis, TNM stage or patient gender and age, while the reduced expression of Beclin1 protein was associated with tumor histology $(\mathrm{P}<0.05)$ and poor differentiation $(\mathrm{P}<0.05)$. Univariate analysis revealed that adenocarcinoma, lymph node metastasis, advanced TNM stage and reduced expression of LKB1 and Beclin1 proteins are associated with the survival of NSCLC patients. Multivariate analysis indicated that adenocarcinoma $(\mathrm{P}<0.05)$, lymph node metastasis $(\mathrm{P}<0.05)$, advanced TNM stage $(\mathrm{P}<0.001)$ and reduced expression of LKB1 $(\mathrm{P}<0.05)$ and Beclin1 $(\mathrm{P}<0.001)$ are all independent prognostic indicators for the survival of NSCLC patients.
\end{abstract}

Correspondence to: Professor Kejun Nan, Department of Oncology, The First Affiliated Hospital of the Medical College of Xi'an Jiaotong University, 277 Yanta West Road, Xi'an, Shaanxi 710061, P.R. China

E-mail: nankejun@126.com

Key words: NSCLC, biomarker, prognosis, LKB1, Beclin1

\section{Introduction}

Lung cancer is the leading cause of cancer-related death in the world and non-small cell lung cancer (NSCLC) accounts for more than $85 \%$ of all diagnosed lung cancers (1). Although advancements have been made in early detection, prevention and treatment options (such as molecular targeting therapy), the overall survival of lung cancer has not significantly improved. Advanced lung cancers are associated with a high rate of metastasis and limited treatment options, all of which contribute to the low 5-year survival rate. Importantly, a large number of patients are still being diagnosed at advanced stages of the disease, which excludes surgery as an option for their treatment. Thus, novel approaches to facilitate early detection and identification and evaluation of prognostic markers could help physicians to more efficiently manage lung cancer patients. At the molecular level, development of lung cancer, similar to most other cancers, involves the activation of oncogenes and inactivation of tumor-suppressor genes and to date, a great number of gene alterations have been identified as being associated with lung carcinogenesis.

One of the molecules involved in tumorigenesis is liver kinase B1 (LKB1, also known as serine/threonine kinase 11, STK11), which is a member of the serine/threonine kinase family and functions to regulate cell polarity. LKB1 was first reported as the causative gene of Peutz-Jeghers syndrome $(2,3)$ characterized by multiple gastrointestinal polyps, mucocutaneous hyperpigmentation and increased cancer risk. The LKB1 protein contains 433 amino acids, a nuclear location signal in the $\mathrm{N}$-terminal non-catalytic domain and the central catalytic domain and a C-terminal non-catalytic domain $(4,5)$. Previous studies have shown that LKB1 functions as a tumor-suppressor gene by activating a group of other kinases, including AMP-activated protein kinase (AMPK) $(6,7)$ or AMPK-related kinases, which in turn regulate cell cycle (8), cell apoptosis, cell polarity and metabolism $(9,10)$. In lung cancer, particularly NSCLC, LKB1 was shown to be frequently mutated or inactivated, and loss of LKB1 function was found to be associated with lung cancer development, tumor de-differentiation, progression and metastasis (11). 
Alteration of autophagy has been shown to play an important role in human tumorigenesis. Although autophagy is considered as an adaptive response to integrated stress, including nutrient deprivation, reactive oxygen species, or endoplasmic reticulum stress (12), it acts as a double-edged sword in cancer. On the one hand, autophagy has tumor-suppressor effects, whereas on the other hand, it can promote tumor survival in response to cellular stress (13). There is preclinical evidence for the improved antitumor effect of chemotherapy when combined with autophagy inhibitors (14-17). In this regard, Beclin1 is a crucial modifier of autophagy and a component of the class III phosphatidylinositol 3-kinase (PI3K) complex that is involved in the activation of autophagy and formation of autophagosomes $(18,19)$. Previous studies have shown aberrant expression of Beclin1 in breast, esophageal, gastric and colorectal cancers (20-22). LKB1 has been demonstrated to be involved in autophagy and regulates the expression of autophagy-related molecules in vitro. A number of preclinical studies have been conducted that demonstrate the utility of targeting LKB1 and autophagy as a therapeutic strategy for several human cancers (23-25). However, the clinicopathological significance of LKB1 and autophagy-related gene Beclin1 and their relationship in vivo remain to be determined. In the present study, we quantified expression of LKB1 and Beclin1 in NSCLC tissues and defined their association with clinicopathological features and survival of the patients.

\section{Materials and methods}

Patients. We collected tissue samples from 142 NSCLC patients who underwent surgery between January 2008 and October 2012 at The First Affiliated Hospital of Xi'an Jiaotong University. The patients were diagnosed with NSCLC based on pathology and did not receive any chemotherapy and/or radiotherapy before surgery. The patient cohort consisted of 82 male and 60 female patients with an average age of 58.2 years (range, 31-84 years). Tumor tissues and matched surrounding normal tissues (at least $5 \mathrm{~cm}$ away from the tumor lesions) were obtained from the Pathology Department. All of the specimens were examined and evaluated by two independent pathologists. Clinicopathological data were collected from the patient medical records and are shown in Table I. Tumor staging was evaluated according to the 7 th edition of the AJCC cancer staging manual (26). The last follow-up date of all patients was recorded in February 2014. For survival analysis, the survival data were censored on the date of the last follow-up or death from causes other than NSCLC. This study was approved by the Medical Ethics Committee of The First Affiliated Hospital of Xi'an Jiaotong University, and informed consent was obtained from each patient.

Immunohistochemistry. Formalin-fixed paraffin-embedded blocks from normal and cancerous tissues were cut into 5- $\mu \mathrm{m}$ sections, deparaffinized and rehydrated in xylene and graded alcohols, respectively. After antigen retrieval by microwave heating in citric acid buffer, the sections were incubated with $3 \% \mathrm{H}_{2} \mathrm{O}_{2}$ for $30 \mathrm{~min}$ at room temperature to block endogenous peroxidase activity. Sections were then incubated with normal serum for $30 \mathrm{~min}$ at room temperature and then further incubated with the primary antibody against LKB1 (D60C5F10;
Cell Signaling Technology, Danvers, MA, USA) at a dilution of 1:250 and Beclin1 (EPR1733Y; Abcam, Cambridge, UK) at a dilution of 1:50 overnight at $4^{\circ} \mathrm{C}$. On the following day, the sections were washed three times with phosphate-buffered saline (PBS) and then incubated with a biotin-labeled secondary antibody. Sections were washed three times with PBS and incubated with 3,3'-diaminobenzidine tetrahydrochloride (DAB) and counterstained with hematoxylin. Breast cancer tissue sections were used as positive controls, and the negative controls were incubated with PBS instead of the primary antibody.

Immunostained tissue sections were then independently reviewed and scored by two clinical pathologists. The scores were based on the staining intensity (0-3) and the percentage of positive-staining tumor cells $(0-100 \%)$. The staining intensity was defined as negative (0), weak (1), moderate (2) or strong (3), and the percentage of positive tumor cells was scored as 0 (0\%), 1 (1-25\%), 2 (26-50\%), 3 (51-75\%) and $4(76-100 \%)$. The staining intensity and the percentage of positive tumor cells were multiplied to reach a final score for each case, which ranged between 0 and 12 , with a score of $0-4$ being considered as low expression of either LKB1 or Beclin1 and a score of 5-12 as high expression of these proteins.

$q R T-P C R$ analysis. Total RNA was extracted from fresh tissues using TRIzol reagent (Invitrogen, Carlsbad, CA, USA) and then reversely transcribed into cDNA using the SYBR ExScript RT-PCR kit (Takara, Dalian, China) according to the manufacturers' instructions. qPCR amplification was then performed using the iQ5 Multicolor Real-Time PCR Detection System (Bio-Rad, Hercules, CA, USA) with SYBR Premix Ex $\mathrm{Taq}^{\mathrm{TM}}$ II (Takara). The PCR primers for LKBl and Beclinl were designed and synthesized by Takara Biotechnology Co. and their sequences were $L K B 1,5$ '-AGCATGACTGTGGTG CCGTACT-3' and 5'-TCCATTGTGACTGGCCTCCTC-3'; Beclin1, 5'-AACCAACGTCTTTAATGCAACCTTC-3' and 5'-AGCAGCATTAATCTCATTCCATTCC-3'. Glyceraldehyde-3-phosphate dehydrogenase $(G A P D H)$ was used as the reference control and the primers were 5'-ATGGGGAAGGT GAAGGTCG-3' and 5'-GGGTCATTGATGGCAACAATA TC-3'. All of the samples were performed in triplicate, and melting curve analysis was conducted to evaluate the specificity of the amplification. The $2^{-\Delta \Delta \mathrm{Ct}}$ method was adopted to quantify levels of the target genes vs. the GAPDH gene. The relative expression $2^{-\Delta \Delta \mathrm{Ct}}$ was calculated using the following formula: $\Delta \mathrm{Ct}=\mathrm{Ct}$ (target) $-\mathrm{Ct}$ (reference); $\Delta \Delta \mathrm{Ct}=\Delta \mathrm{Ct}$ (tumor) $-\Delta \mathrm{Ct}$ (normal).

Protein extraction and western blotting. Total cellular protein for western blotting was extracted from the fresh tissues using RIPA lysis buffer (Beyotime Chemical Co., Beijing, China). The protein samples were separated on 6-12\% sodium dodecyl sulfate-polyacrylamide gel electrophoresis (SDS-PAGE) and transferred onto PVDF membranes (Millipore Corp., Billerica, MA, USA). For western blotting, the PVDF membranes were blocked in 5\% non-fat milk at room temperature for $1 \mathrm{~h}$ and then incubated with primary antibodies (anti-LKB1 antibody, 1:800, 27D10, Cell Signaling Technology; anti-Beclin1 antibody, 1:800, EPR1733Y, Abcam and anti- $\beta$-actin antibody, 1:1000, sc-130301, Santa Cruz Biotechnology Inc., Santa 
Table I. Association of LKB1 and Beclin1 protein expression with clinicopathological parameters of the NSCLC patients.

\begin{tabular}{|c|c|c|c|c|c|c|c|}
\hline \multirow[b]{2}{*}{ Characteristics } & \multirow[b]{2}{*}{$\mathrm{n}$} & \multicolumn{2}{|c|}{ LKB1 expression } & \multirow[b]{2}{*}{ P-value } & \multicolumn{2}{|c|}{ Beclin1 expression } & \multirow[b]{2}{*}{ P-value } \\
\hline & & Low & High & & Low & High & \\
\hline All cases & 142 & & & & & & \\
\hline Gender & & & & 0.408 & & & 0.666 \\
\hline Male & 82 & 17 & 65 & & 33 & 49 & \\
\hline Female & 60 & 16 & 44 & & 22 & 38 & \\
\hline Age (years) & & & & 0.721 & & & 0.186 \\
\hline$<60$ & 77 & 17 & 60 & & 26 & 51 & \\
\hline$\geq 60$ & 65 & 16 & 49 & & 29 & 36 & \\
\hline Histologic type & & & & $<0.001$ & & & 0.032 \\
\hline $\mathrm{ADC}$ & 83 & 28 & 55 & & 26 & 57 & \\
\hline SQCC & 59 & 5 & 54 & & 29 & 30 & \\
\hline Differentiation & & & & $<0.001$ & & & 0.015 \\
\hline Poor & 57 & 23 & 34 & & 29 & 28 & \\
\hline Moderate to well & 85 & 10 & 75 & & 26 & 59 & \\
\hline Lymph node metastasis & & & & 0.150 & & & 0.166 \\
\hline No & 80 & 15 & 65 & & 27 & 53 & \\
\hline Yes & 62 & 18 & 44 & & 28 & 34 & \\
\hline TNM stage & & & & 0.075 & & & 0.076 \\
\hline I-II & 107 & 21 & 86 & & 37 & 70 & \\
\hline III-IV & 35 & 12 & 23 & & 18 & 17 & \\
\hline
\end{tabular}

LKB1, liver kinase B1; NSCLC, non-small cell lung cancer; ADC, adenocarcinoma; SQCC, squamous cell carcinoma.

Cruz, CA, USA) at $4^{\circ} \mathrm{C}$ overnight. On the following day, the membranes were washed with PBS-Tween-20 (PBS-T) three times and then incubated with the secondary antibody (Santa Cruz Biotechnology) and the immunoreaction was detected using the ECL reagent (Millipore Corp.). Each experiment was repeated twice, and the band intensities were quantified by densitometry.

Statistical analysis. Pearson's $\chi^{2}$ test was used to determine an association between expression of LKB1 or Beclin1 and the clinicopathological parameters. Independent t-test was adopted to assess the statistical significance of differences between cancer and the matched surrounding normal tissues. Spearman's test was used to assess the correlation between LKB1 and Beclin1 expression. Survival curves were calculated using the Kaplan-Meier method and statistically analyzed using the log-rank test. For univariate and multivariate analyses, Cox regression model was carried out to estimate the prognostic value of the clinicopathological factors and expression of LKB1 and Beclin1. Statistical analyses were carried out using SPSS 17.0 software (SPSS, Chicago, IL, USA). $\mathrm{P}<0.05$ was defined as statistically significant.

\section{Results}

Expression of LKBI in NSCLC and paired surrounding normal tissues. We performed qRT-PCR, western blotting and immunohistochemistry to assess the expression of LKB1 and
Beclin1 in 142 paired normal and NSCLC tissue specimens. The data showed that the level of $L K B 1$ mRNA was significantly lower in the NSCLC tissues than that in the normal lung tissues $(\mathrm{P}<0.001)$. Reduced levels of $L K B 1 \mathrm{mRNA}$ were associated with tumor histology $(\mathrm{P}=0.041)$ and de-differentiation $(\mathrm{P}=0.006)$ (Table II). Immunohistochemical staining revealed that LKB1 protein was moderately or strongly expressed in the cytoplasm (Fig. 1). One hundred and nine (76.8\%) cases of NSCLC tissues expressed LKB1 protein but the expression level was significantly lower than that in the surrounding normal lung tissues $(\mathrm{P}<0.001)$. Reduced expression of LKBI protein was associated with tumor histologic type $(\mathrm{P}<0.001)$ and de-differentiation $(\mathrm{P}<0.001)$, but not with lymph node metastasis and advanced TNM stage or with patient gender and age (Table I). Similarly, western blotting was consistent with the immunohistochemical data, showing that LKB1 was expressed in $71.8 \%(102 / 142)$ of NSCLC tissues and in $89.4 \%$ (127/142) of surrounding normal lung tissues (Fig. 2). LKB1 expression was significantly lower in the NSCLC than that in paired normal lung tissues.

Expression of Beclinl in NSCLC and paired surrounding normal tissues. Beclin1 protein was predominantly expressed in the cytoplasm of both normal and tumor lung tissues. In NSCLC tissues, Beclin1 protein expression was observed in $87(61.3 \%)$ cases, which was lower than that in the normal lung tissues (Fig. 1). Reduced expression of Beclin1 was significantly associated with tumor histologic type $(\mathrm{P}=0.032)$ and 
Table II. Association of LKB1 and Beclin1 mRNA levels with the clinicopathological parameters of the NSCLC patients.

\begin{tabular}{|c|c|c|c|c|c|c|c|}
\hline \multirow[b]{2}{*}{ Characteristics } & \multirow[b]{2}{*}{$\mathrm{n}$} & \multicolumn{2}{|c|}{$\begin{array}{l}\text { LKB1 mRNA } \\
\text { expression }\end{array}$} & \multirow[b]{2}{*}{ P-value } & \multicolumn{2}{|c|}{$\begin{array}{c}\text { Beclin } 1 \text { mRNA } \\
\text { expression }\end{array}$} & \multirow[b]{2}{*}{ P-value } \\
\hline & & Low & High & & Low & High & \\
\hline All cases & 142 & & & & & & \\
\hline Gender & & & & 0.419 & & & 0.927 \\
\hline Male & 82 & 37 & 45 & & 43 & 39 & \\
\hline Female & 60 & 23 & 37 & & 31 & 29 & \\
\hline Age (years) & & & & 0.601 & & & 0.704 \\
\hline$<60$ & 77 & 31 & 46 & & 39 & 38 & \\
\hline$\geq 60$ & 65 & 29 & 36 & & 35 & 30 & \\
\hline Histologic type & & & & 0.041 & & & 0.005 \\
\hline $\mathrm{ADC}$ & 83 & 41 & 42 & & 35 & 48 & \\
\hline SQCC & 59 & 19 & 40 & & 39 & 20 & \\
\hline Differentiation & & & & 0.006 & & & 0.031 \\
\hline Poor & 57 & 32 & 25 & & 36 & 21 & \\
\hline Moderate to well & 85 & 28 & 57 & & 38 & 47 & \\
\hline Lymph node metastasis & & & & 0.193 & & & 0.112 \\
\hline No & 80 & 30 & 50 & & 37 & 43 & \\
\hline Yes & 62 & 30 & 32 & & 37 & 25 & \\
\hline TNM stage & & & & 0.097 & & & 0.282 \\
\hline I-II & 107 & 41 & 66 & & 53 & 54 & \\
\hline III-IV & 35 & 19 & 16 & & 21 & 14 & \\
\hline
\end{tabular}

NSCLC patients were divided into two groups by the gene median expression. LKB1, liver kinase B1; NSCLC, non-small cell lung cancer; ADC, adenocarcinoma; SQCC, squamous cell carcinoma.

de-differentiation $(\mathrm{P}=0.015)$. However, there was no significant association with patient gender and age, tumor lymph node metastasis or TNM stage (Table I). Similar results were observed in data from the western blot analysis. Beclin1 protein was expressed in $40.1 \%$ (57/142) of NSCLC tissues, which was significantly lower than that of the paired surrounding normal lung tissues $(72.5 \%, 103 / 142)$. Furthermore, levels of Beclin1 mRNA were also significantly lower in the NSCLC tissues than that in the paired normal lung tissues. The reduced Beclinl mRNA level was also associated with tumor histology $(\mathrm{P}=0.005)$ and de-differentiation $(\mathrm{P}=0.031)$.

Correlation of LKB1 and Beclinl expression in NSCLC tissue specimens. Since LKB1 and Beclin1 are being targeted for clinical control of different human cancers, we examined the possible correlation between these two proteins in terms of their expression in NSCLC tissue samples using Spearman's rank test. We found that $\mathrm{LKB} 1$ protein expression was statistically correlated $(\mathrm{r}=0.247, \mathrm{P}=0.003)$ with Beclin1 expression (Table III). However, there was no correlation between levels of LKB1 and Beclin1 mRNA ( $\mathrm{r}=0.135, \mathrm{P}=0.109)$.

Association of LKB1 and Beclinl protein expression with overall survival of NSCLC patients. All 142 patients were followed up until February 2014. We found that the median
Table III. Correlation of LKB1 with Beclin1 expression in the NSCLC tissues.

Beclin1 expression
Low High

\begin{tabular}{llll}
\hline LKB1 expression & & & \\
Low & 20 & 13 & \\
High & 35 & 74 & 0.003 \\
\hline
\end{tabular}

LKB1, liver kinase B1; NSCLC, non-small cell lung cancer.

survival time of these patients was 31 months (range 3-71 months). The Kaplan-Meier curves were then plotted after stratification based on LKB1 and Beclin1 protein expression and analyzed using the log-rank test. The overall survival of NSCLC patients with low LKB1 or Beclin1 expression was significantly shorter than that of patients with high LKB1 or Beclin1 expression (Fig. 3). In order to evaluate the prognostic significance of the combined LKB1 and Beclin1 expression, NSCLC patients were classified into four subgroups: $\mathrm{LKB}^{+} /$Beclin $^{+}$, LKB1 $1^{+}$Beclin $1^{-}$, LKB1 $1^{-/ B e c l i n} 1^{-}$and LKB1 $1^{-}$Beclin $1^{+}$. We found that patients without LKB1 and 

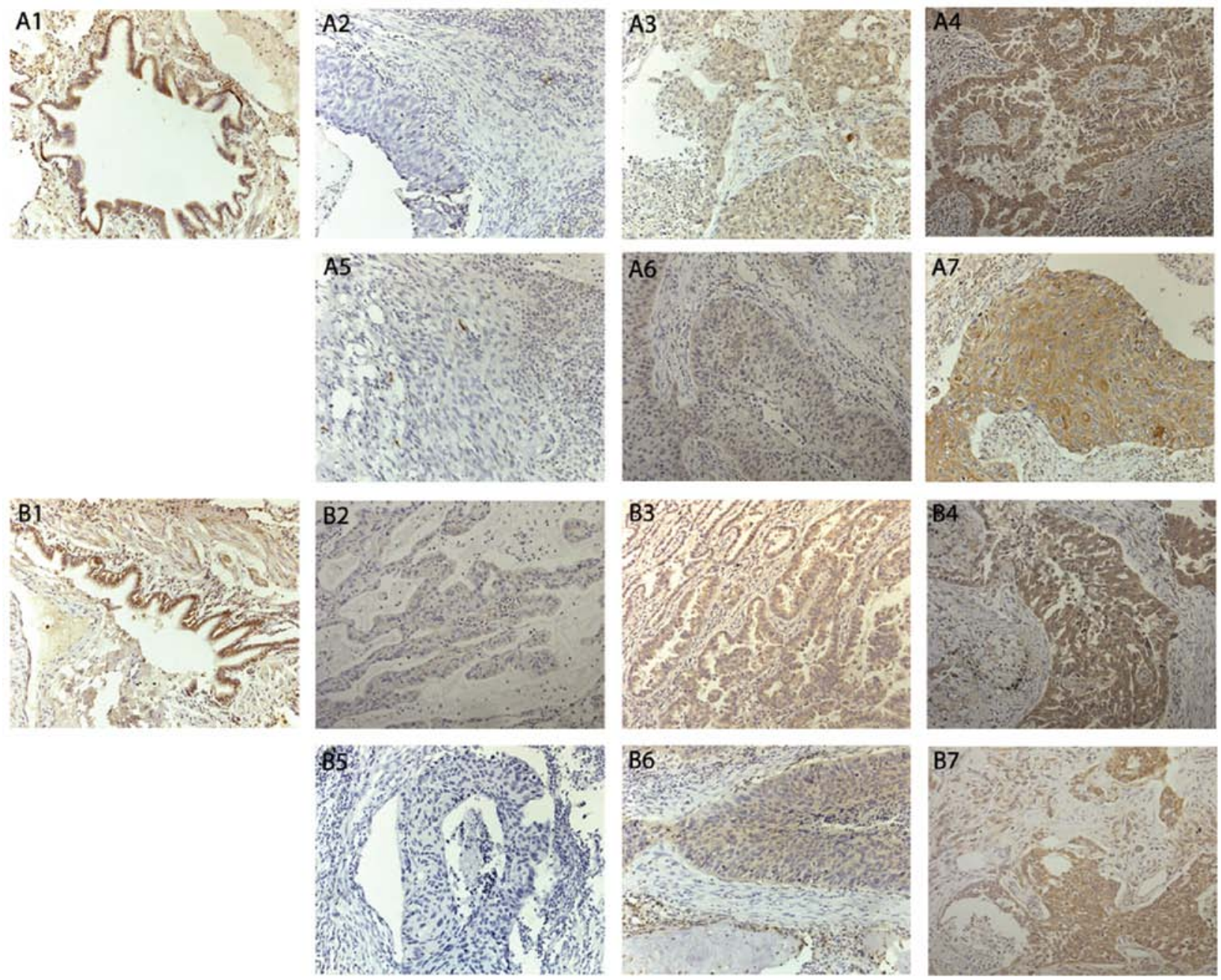

Figure 1. Immunohistochemical staining of LKB1 and Beclin1 proteins in NSCLC tissues (magnification, x200). Immunohistochemical expression of LKB1 in paired normal lung tissues (A1), lung adenocarcinoma (A2-A4) and lung squamous cell carcinoma (A5-A7). Immunohistochemical expression of Beclin1 in paired normal lung tissues (B1), lung adenocarcinoma (B2-B4) and lung squamous cell carcinoma (B5-B7). (A2, A5, B2, B5) weak expression, (A3, A6, B3, B6) moderate expression and (A4, A7, B4, B7) strong expression. LKB1, liver kinase B1; NSCLC, non-small cell lung cancer.

A

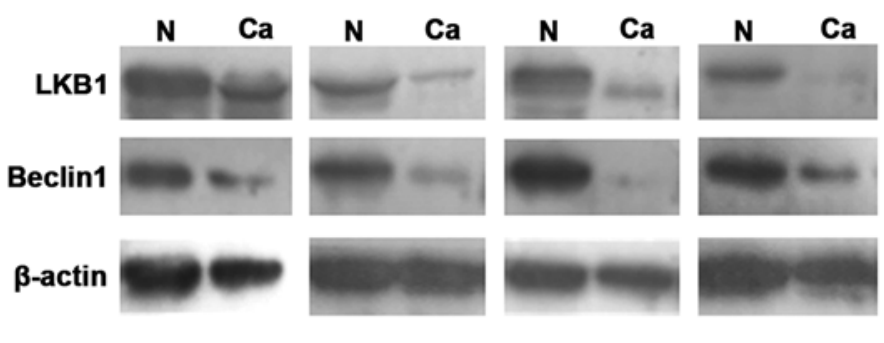

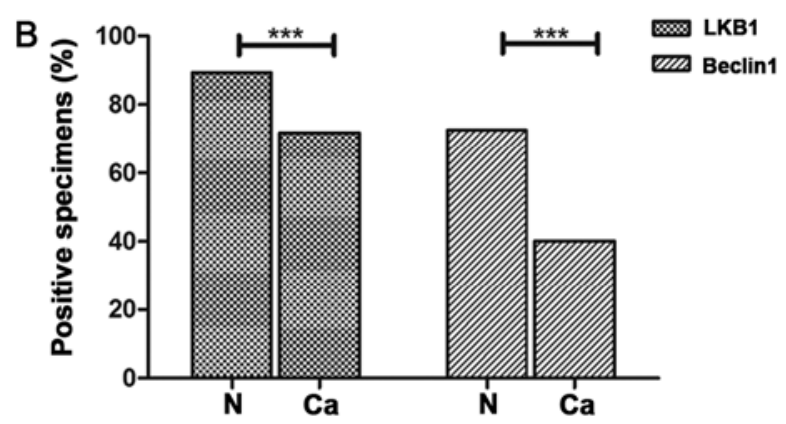

Figure 2. Western blotting of LKB1 and Beclin1 proteins in NSCLC (Ca) and the paired surrounding normal (N) tissues from four patients. (A) Western blotting and (B) quantitative data of the western blots. ${ }^{* * *} \mathrm{P}<0.001$. LKB1, liver kinase B1; NSCLC, non-small cell lung cancer.

Beclin1 expression had a poorer overall survival than the other three groups of patients (Fig. 3). Univariate and multivariate Cox proportional hazards models (Table IV) were established to assess prognostic indicators using clinicopathological data and LKB1 and Beclin1 expression. Specifically, univariate analysis showed that adenocarcinoma $(\mathrm{P}=0.011)$, lymph node metastasis $(\mathrm{P}<0.001)$, advanced TNM stage $(\mathrm{P}<0.001)$ and reduced expression of LKB1 [Exp (B), 0.31; 95\% CI, 0.18-0.54; $\mathrm{P}<0.001]$ and Beclin1 [Exp (B), 0.38; 95\% CI, 0.23$0.63 ; \mathrm{P}<0.001]$ all predicted shorter overall survival of NSCLC patients. Multivariate analysis further showed that adenocarcinoma, lymph node metastasis, advanced TNM stage and reduced expression of LKB1 and Beclin1 are all independent indicators for overall survival of the NSCLC patients. 

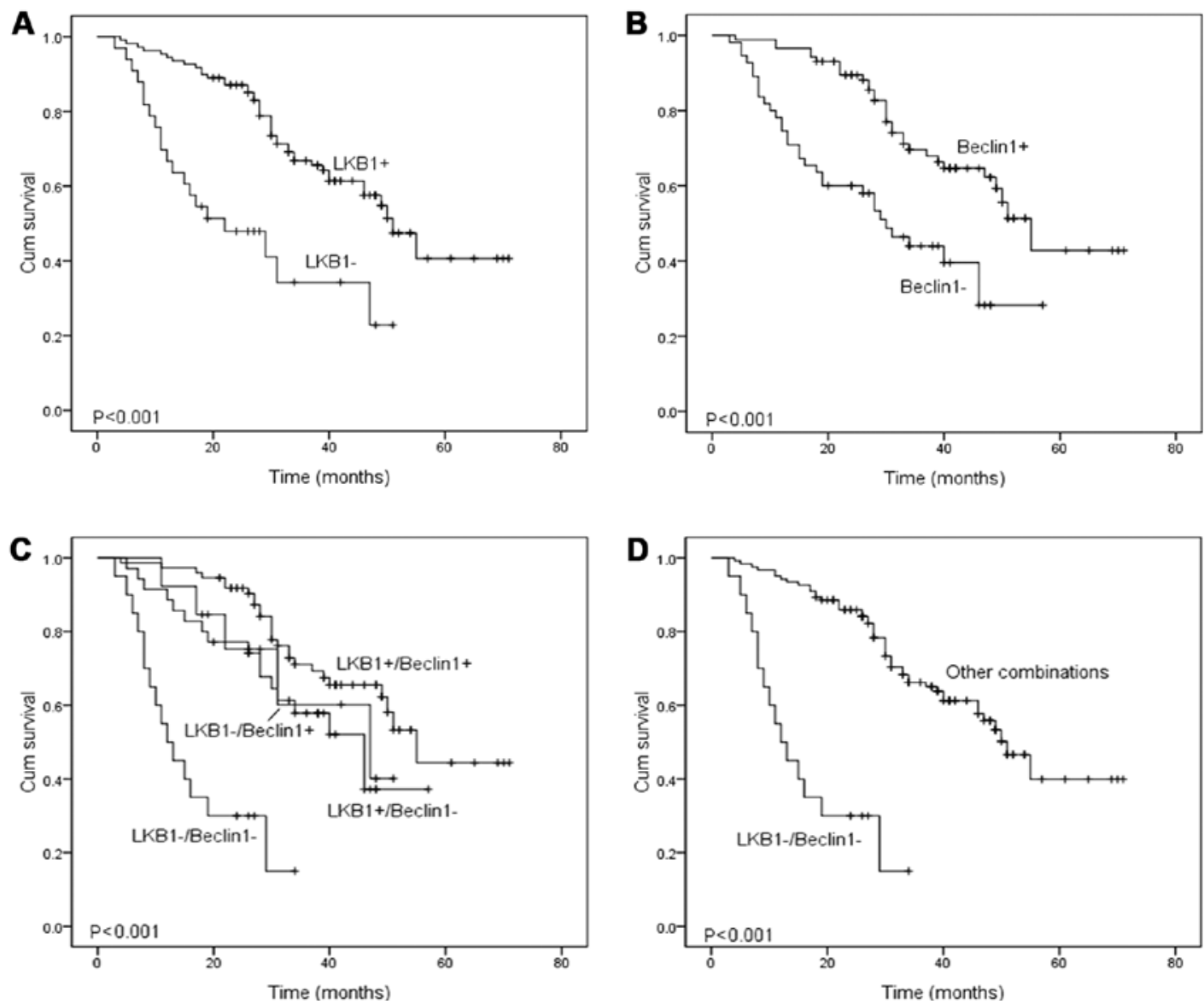

Figure 3. Kaplan-Meier survival curves stratified by LKB1 and Beclin1 expression in NSCLC patients. (A) Overall survival according to LKB1 expression. (B) Overall survival according to Beclin1 expression. (C) Overall survival according to LKB1 ${ }^{+} / \mathrm{Beclin}^{+}, \mathrm{LKB1}^{+} / \mathrm{Beclin1}^{-}, \mathrm{LKB1}^{-} / \mathrm{Beclin}^{-}$and $\mathrm{LKB1}^{-/ B} \mathrm{Beclin} 1^{+}$ status. (D) Overall survival of patients without LKB1/Beclin1 expression vs. the other three groups of patients. LKB1, liver kinase B1; NSCLC, non-small cell lung cancer.

\section{Discussion}

In the present study, we detected expression of LKB1 and Beclin1 mRNA and protein in 142 NSCLC and paired surrounding normal lung tissues. We found that expression of both LKB1 and Beclin1 mRNA and protein was reduced significantly in the NSCLC tissues compared to levels in the normal tissues. Expression of LKB1 protein was correlated with Beclin1 expression in the NSCLC tissues and the reduced expression of $L K B 1$ and Beclinl mRNA and proteins was associated with tumor histology and de-differentiation. Furthermore, the reduced expression of both LKB1 and Beclin1 proteins was associated with poor overall survival of the NSCLC patients. Patients without LKB1 and Beclin1 expression had a poorer overall survival than the other three groups of patients. Multivariate analysis confirmed that expression of both LKB1 and Beclin1 proteins, together with adenocarcinoma, lymph node metastasis and advanced TNM stage, are independent indicators for the overall survival of NSCLC patients. Thus, future studies are required to further evaluate these molecules as biomarkers for NSCLC prognosis.

Our current data are consistent with previous studies. LKB1 inactivation is common in lung adenocarcinoma $(27,28)$ and plays a role as a tumor biomarker in mouse and human tissues (29). Furthermore, inactivation of $L K B 1$ via somatic mutations commonly occurs in NSCLC, and loss of function mutations of $L K B 1$ have been reported in $\sim 20-30 \%$ of NSCLC patients (30). A mutation analysis also identified $L K B 1$ mutations in other cancers, such as melanoma, cervical, pancreatic and prostate cancers (31-33). Ji et al (11) provided strong evidence that LKB1 plays a key role in lung cancer differentiation and metastasis. In addition, mouse models of LKB1 heterozygous deletion showed that the $L K B 1$ deletion is sufficient to induce cancer development in mice (34-36). However, Onozato et al (37) showed that there was no statistically significant correlation between patient survival curves and expression of $L K B 1 \mathrm{mRNA}$.

At the cellular level, LKB1 can induce or prevent apoptosis, depending on the cell context. This is due to the fact that LKB1 is also involved in autophagy, considered as type II programmed cell death. Autophagy is a self-digesting process that degrades and recycles aged protein and organelles engulfed into autophagosomes through the lysosomal pathway (38). Autophagy is a highly conserved degradation process regulated by autophagy-related genes. Several diseases, such as neurodegenerative, cancer, ageing and certain liver and heart diseases are related to dysfunctional autophagy (39). The current theory suggests that autophagy can act as a tumor suppressor or cell apoptosis protector. A previous study showed that LKB1 activated autophagy through AMPK activation to inhibit mTOR and protected from cell death (6). The LKB1-AMPK pathway can be activated by energy stress and 
Table IV. Univariate and multivariate analyses of the overall survival of 142 NSCLC patients.

\begin{tabular}{|c|c|c|c|c|c|}
\hline \multirow[b]{2}{*}{ Characteristics } & \multirow[b]{2}{*}{$\mathrm{n}$} & \multicolumn{2}{|c|}{ Overall survival/univariate } & \multicolumn{2}{|c|}{ Overall survival/multivariate } \\
\hline & & HR $(95 \%$ CI $)$ & P-value & $\mathrm{HR}(95 \% \mathrm{CI})$ & P-value \\
\hline \multicolumn{6}{|l|}{ Gender } \\
\hline Male & 82 & 1 & & & \\
\hline Female & 60 & $1.45(0.88-2.37)$ & 0.145 & & \\
\hline \multicolumn{6}{|l|}{ Age (years) } \\
\hline$<60$ & 77 & 1 & & & \\
\hline$\geq 60$ & 65 & $1.13(0.69-1.85)$ & 0.637 & & \\
\hline \multicolumn{6}{|l|}{ Histologic type } \\
\hline ADC & 83 & 1 & & 1 & \\
\hline SQCC & 59 & $0.50(0.29-0.85)$ & 0.011 & $0.37(0.20-0.67)$ & 0.001 \\
\hline \multicolumn{6}{|l|}{ Differentiation } \\
\hline Poor & 57 & 1 & & & \\
\hline Moderate to well & 85 & $0.84(0.51-1.36)$ & 0.490 & & \\
\hline \multicolumn{6}{|c|}{ Lymph node metastasis } \\
\hline No & 80 & 1 & & 1 & \\
\hline Yes & 62 & $4.34(2.54-7.42)$ & $<0.001$ & $2.21(1.17-4.17)$ & 0.015 \\
\hline \multicolumn{6}{|l|}{ TNM stage } \\
\hline I-II & 107 & 1 & & 1 & \\
\hline III-IV & 35 & $5.97(3.56-10.01)$ & $<0.001$ & $4.80(2.51-9.17)$ & $<0.001$ \\
\hline \multicolumn{6}{|l|}{ LKB1 } \\
\hline Low & 33 & 1 & & 1 & \\
\hline High & 109 & $0.31(0.18-0.54)$ & $<0.001$ & $0.47(0.25-0.88)$ & 0.018 \\
\hline \multicolumn{6}{|l|}{ Beclin1 } \\
\hline Low & 55 & 1 & & 1 & \\
\hline High & 87 & $0.38(0.23-0.63)$ & $<0.001$ & $0.26(0.15-0.48)$ & $<0.001$ \\
\hline
\end{tabular}

NSCLC, non-small cell lung cancer; ADC, adenocarcinoma; SQCC, squamous cell carcinoma; LKB1, liver kinase B1.

ROS. Moreover, Beclin1 directly participates in autophagy regulation, and altered Beclin1 expression is associated with human tumorigenesis. Indeed, the present data showed that expression of Beclin1 mRNA and protein was significantly reduced in NSCLC tissues compared to that in the paired surrounding normal lung tissues, which is consistent with previous studies of NSCLC $(40,41)$. However, Ahn et al (22) showed that Beclin1 expression in gastric and colorectal cancer was notably higher than that in paired normal tissues. The reason for this discrepancy is not known, but it may be tissue-specific. In addition, our present data showed that Beclin1 expression was associated with tumor histology and differentiation and with overall survival of NSCLC patients. We also found that low LKB1 expression was significantly correlated with low Beclin1 expression. We therefore propose that LKB1 may influence tumor differentiation and metastasis through autophagy. However, the exact molecular mechanisms require further investigation.

In conclusion, the present study demonstrated that expression of LKB1 and Beclin1 was reduced in NSCLC tissues, and the reduced expression of these proteins, together with adenocarcinoma, lymph node metastasis and advanced TNM stage, are independent indicators for the overall survival of NSCLC patients. Further studies to verify our data are required before translation into clinical practice.

\section{Acknowledgements}

This study was supported in part by a grant from the National Natural Science Foundation of China (nos. 81101777 and 8130190). The authors would like to thank Professsor Chen Huang of Xi'an Jiaotong University for the technical support.

\section{References}

1. Siegel R, Ma J, Zou Z and Jemal A: Cancer statistics, 2014. CA Cancer J Clin 64: 9-29, 2014.

2. Hemminki A, Markie D, Tomlinson I, et al: A serine/threonine kinase gene defective in Peutz-Jeghers syndrome. Nature 391: 184-187, 1998.

3. Jenne DE, Reomann H, Nezu J, et al: Peutz-Jeghers syndrome is caused by mutations in a novel serine threonine kinase. Nat Genet 18: 38-43, 1998.

4. Smith DP, Spicer J, Smith A, Swift S and Ashworth A: The mouse Peutz-Jeghers syndrome gene $L k b l$ encodes a nuclear protein kinase. Hum Mol Genet 8: 1479-1485, 1999. 
5. Boudeau J, Kieloch A, Alessi DR, Stella A, Guanti G and Resta N: Functional analysis of LKB1/STK11 mutants and two aberrant isoforms found in Peutz-Jeghers syndrome patients. Hum Mutat 21: 172, 2003.

6. Shackelford DB and Shaw RJ: The LKB1-AMPK pathway: metabolism and growth control in tumour suppression. Nat Rev Cancer 9: 563-575, 2009.

7. Kahn BB, Alquier T, Carling D and Hardie DG: AMP-activated protein kinase: ancient energy gauge provides clues to modern understanding of metabolism. Cell Metab 1: 15-25, 2005.

8. Baas AF, Boudeau J, Sapkota GP, et al: Activation of the tumour suppressor kinase LKB1 by the STE20-like pseudokinase STRAD. EMBO J 22: 3062-3072, 2003

9. Nakada D, Saunders TL and Morrison SJ: Lkb1 regulates cell cycle and energy metabolism in haematopoietic stem cells Nature 468: 653-658, 2010.

10. Jansen M, Ten Klooster JP, Offerhaus GJ and Clevers H: LKB1 and AMPK family signaling: the intimate link between cell polarity and energy metabolism. Physiol Rev 89: 777-798, 2009.

11. Ji H, Ramsey MR, Hayes DN, et al: LKB1 modulates lung cancer differentiation and metastasis. Nature 448: 807-810, 2007.

12. Kroemer G, Mariño G and Levine B: Autophagy and the integrated stress response. Mol Cell 40: 280-293, 2010.

13. White E and DiPaola RS: The double-edged sword of autophagy modulation in cancer. Clin Cancer Res 15: 5308-5316, 2009.

14. Carew JS, Nawrocki ST, Kahue CN, et al: Targeting autophagy augments the anticancer activity of the histone deacetylase inhibitor SAHA to overcome Bcr-Abl-mediated drug resistance. Blood 110: 313-322, 2007.

15. Michaud M, Martins I, Sukkurwala AQ, et al: Autophagy-dependent anticancer immune responses induced by chemotherapeutic agents in mice. Science 334: 1573-1577, 2011.

16. Moretti L, Yang ES, Kim KW and Lu B: Autophagy signaling in cancer and its potential as novel target to improve anticancer therapy. Drug Resist Updat 10: 135-143, 2007.

17. Liu YL, Yang PM, Shun CT, Wu MS, Weng JR and Chen CC: Autophagy potentiates the anti-cancer effects of the histone deacetylase inhibitors in hepatocellular carcinoma. Autophagy 6 : 1057-1065, 2010.

18. Choi AM, Ryter SW and Levine B: Autophagy in human health and disease. N Engl J Med 368: 651-662, 2013

19. Wrighton KH: Autophagy: kinase crosstalk through beclin 1. Nat Rev Mol Cell Biol 14: 402-403, 2013.

20. Won KY, Kim GY, Kim YW, Song JY and Lim SJ: Clinicopathologic correlation of beclin-1 and bcl-2 expression in human breast cancer. Hum Pathol 41: 107-112, 2010.

21. Chen Y, Lu Y, Lu C and Zhang L: Beclin-1 expression is a predictor of clinical outcome in patients with esophageal squamous cell carcinoma and correlated to hypoxia-inducible factor (HIF)-1 $\alpha$ expression. Pathol Oncol Res 15: 487-493, 2009.

22. Ahn CH, Jeong EG, Lee JW, et al: Expression of beclin-1, an autophagy-related protein, in gastric and colorectal cancers. APMIS 115: 1344-1349, 2007.

23. Chen N and Karantza V: Autophagy as a therapeutic target in cancer. Cancer Biol Ther 11: 157-168, 2011.
24. Chen S, Rehman SK, Zhang W, Wen A, Yao L and Zhang J: Autophagy is a therapeutic target in anticancer drug resistance. Biochim Biophys Acta 1806: 220-229, 2010.

25. Alexander A and Walker CL: The role of LKB1 and AMPK in cellular responses to stress and damage. FEBS Lett 585: 952-957, 2011.

26. Edge SB and Compton CC: The American Joint Committee on Cancer: the 7th edition of the AJCC cancer staging manual and the future of TNM. Ann Surg Oncol 17: 1471-1474, 2010.

27. Shackelford DB, Abt E, Gerken L, et al: LKB1 inactivation dictates therapeutic response of non-small cell lung cancer to the metabolism drug phenformin. Cancer Cell 23: 143-158, 2013.

28. Sanchez-Cespedes M, Parrella P, Esteller M, et al: Inactivation of $L K B 1 / S T K 11$ is a common event in adenocarcinomas of the lung. Cancer Res 62: 3659-3662, 2002.

29. Nakada Y, Stewart TG, Peña CG, et al: The LKB1 tumor suppressor as a biomarker in mouse and human tissues. PLoS One 8: e73449, 2013.

30. Matsumoto S, Iwakawa $\mathrm{R}$, Takahashi $\mathrm{K}$, et al: Prevalence and specificity of $L K B 1$ genetic alterations in lung cancers. Oncogene 26: 5911-5918, 2007.

31. Wingo SN, Gallardo TD, Akbay EA, et al: Somatic LKB1 mutations promote cervical cancer progression. PLoS One 4: e5137, 2009.

32. Su GH, Hruban RH, Bansal RK, et al: Germline and somatic mutations of the STK11/LKB1 Peutz-Jeghers gene in pancreatic and biliary cancers. Am J Pathol 154: 1835-1840, 1999.

33. Rowan A, Bataille V, MacKie R, et al: Somatic mutations in the Peutz-Jegners (LKB1/STKII) gene in sporadic malignant melanomas. J Invest Dermatol 112: 509-511, 1999.

34. Nakau M, Miyoshi H, Seldin MF, Imamura M, Oshima M and Taketo MM: Hepatocellular carcinoma caused by loss of heterozygosity in $L k b 1$ gene knockout mice. Cancer Res 62: 4549-4553, 2002 .

35. Miyoshi H, Nakau M, Ishikawa TO, Seldin MF, Oshima M and Taketo MM: Gastrointestinal hamartomatous polyposis in $L k b l$ heterozygous knockout mice. Cancer Res 62: 2261-2266, 2002.

36. McCarthy A, Lord CJ, Savage K, et al: Conditional deletion of the $L k b l$ gene in the mouse mammary gland induces tumour formation. J Pathol 219: 306-316, 2009.

37. Onozato R, Kosaka T, Achiwa $\mathrm{H}$, et al: $L K B 1$ gene mutations in Japanese lung cancer patients. Cancer Sci 98: 1747-1751, 2007.

38. Klionsky DJ and Emr SD: Autophagy as a regulated pathway of cellular degradation. Science 290: 1717-1721, 2000.

39. Levine B and Kroemer G: Autophagy in the pathogenesis of disease. Cell 132: 27-42, 2008

40. Liu J, Lin Y, Yang H, Deng Q, Chen G and He J: The expression of p33(ING1), p53, and autophagy-related gene Beclin1 in patients with non-small cell lung cancer. Tumour Biol 32: 1113-1121, 2011.

41. Kim KM, Yu TK, Chu HH, et al: Expression of ER stress and autophagy-related molecules in human non-small cell lung cancer and premalignant lesions. Int J Cancer 131: E362-E370, 2012. 